\title{
Breast cancer cases of female patients under 35 years of age in Togo: A series of 158 cases
}

\author{
TCHIN DARRÉ ${ }^{1}$, MAZAMAESSO TCHAOU ${ }^{2}$, KOUÉ FOLLIGAN $^{3}$, \\ ABDOULATIF AMADOU ${ }^{2}$, BIDAMIN N'TIMON ${ }^{2}$, LANTAM SONHAYE $^{2}$, \\ ABDOUL-SAMADOU ABOUBAKARI ${ }^{4}$, KOFFI AMÉGBOR ${ }^{1}$, KOFFI AKPADZA $^{4}$ and GADO NAPO KOURA ${ }^{1}$
}

Departments of ${ }^{1}$ Pathology, ${ }^{2}$ Imaging and ${ }^{3}$ Histology-Embryology, The University Teaching Hospital of Lomé, Lomé BP1515; ${ }^{4}$ Department of Obstetrics and Gynecology, University Teaching Hospital of Lomé and Kara, Kara BP18, Togo

Received April 26, 2017; Accepted September 28, 2017

DOI: $10.3892 / \mathrm{mco} .2017 .1461$

\begin{abstract}
Breast cancer in young female patients represents a public health problem in developing countries. The objectives of the study were to study the epidemiological and histological characteristics of breast cancer in female patients under 35 years of age. This was a retrospective analytical study of a series of 158 cases of breast cancer in female patients under 35 years of age, conducted at the University Teaching Hospital of Lomé between 2000 and 2015. A total of 158 cases were collected, representing 36.2\% (436) of all breast cancer cases. The average age of the patients was 30.9 years (range, 16-35 years). A family history of breast cancer at the 1st or 2nd degree was identified in $13.9 \%$ of cases. Genetic mutation studies were carried out for 7 patients, 5 of which revealed mutations (4 BRCA1 and 1 BRCA2). According to the locus, the cancer was located preferentially in the left breast in 88 cases $(55.7 \%)$. Malignant mammary lesions were epithelial tumors ( $\mathrm{n}=144$ cases, $91.1 \%)$, infiltrating $(\mathrm{n}=125$ cases, $79.1 \%)$ and non-infiltrating ( $\mathrm{n}=19$ cases, $12.0 \%)$. The other histological groups consisted of 8 cases of sarcomas ( 5 cases of angiosarcoma, 2 cases of fibrosarcoma and 1 case of Kaposi's sarcoma), 5 cases of lymphomas and one case of melanoma. Not otherwise specified infiltrating ductal carcinomas were SBR II and III in 43.2 and $35.2 \%$ of cases, respectively. The tumors classified as T4 were the most frequent (30.4\%). Regarding the lymph node status, lymph node metastasis was noted in $22.8 \%$ of cases. Studies of hormone receptors were carried out in 23 patients and were positive for 11 patients: Estrogen receptor (ER)+plus progesterone receptor (PR)+(7 patients), ER+PR-(4 patients). Of the aforementioned 8 cases of sarcoma, 5 were angiosarcoma. The lymphomas were predominantly Burkitt's type for 4 cases. Mammary ultrasonography was performed in $45.6 \%$
\end{abstract}

Correspondence to: Dr Tchin Darré, Department of Pathology, The University Teaching Hospital of Lomé, Bld Gnassingbé Eyadema, Lomé BP1515, Togo

E-mail: paolodarre@yahoo.fr

Key words: cancer breast, cancer registry, carcinoma, immunohistochemistry, Togo, Africa of the patients and 54.4\% underwent the combined ultrasonography and mammography. Ultrasound identified one or more sign of malignancy in 67 patients (42.4\%), and combined ultrasonography and mammography classified $51.9 \%$ of lesions in BIRADS 4 and 5. The incidence of breast cancer in young Togolese patients is high. It is a disease distinguished by a delay in diagnosis, which contributes to the high number of cases that initially diagnosed at an advanced stage, particularly the high histo-prognosis grades of infiltrating ductal carcinoma. These results indicate a genetic origin; therefore, a thorough investigation into genetic mutations should be carried. In addition, further collaborative studies are required to verify these results.

\section{Introduction}

Breast cancer is the most-diagnosed type of cancer in female patients worldwide, accounting for $\sim 25 \%$ of cancer cases in females; it has a higher prevalence in developed countries and an average age of onset of 50-70 years $(1,2)$. Breast cancer in young female patients is increasingly common and presents a real problem for the diagnosis and adequate management of the disease in developing countries (2). In the USA and Europe, the incidence of breast cancer in female patients $\leq 35$ years of age varies from $3-24 \%(3,4)$. The incidence is increasing in younger female patients globally with their own epidemiological, diagnostic and prognostic characteristics (5). In France 2006, 4,000 females under 35 were diagnosed with breast cancer. Since tumors are more aggressive in younger women, it is important that they are diagnosed and treated early (3). Breast cancer in younger patients is notable health issue considering the major medical issues and psychological distress associated with this diagnosis. In young female patients, from an epidemiological viewpoint, genetic predisposition must be considered. Hereditary forms of breast cancer are rare and affect $<10 \%$ of young female patients with the disease, with only three contributing genes currently recognized: BRCA 1 and BRCA 2, for which mutations have frequently been identified in young female patients with breast cancer (4).

Regarding radiological screening of any mammary symptoms in females under the age of 35 years, ultrasound should 
be performed as a first-line diagnosis test. The breast tissue of young females is dense, with a satisfactory echogenicity allowing the effective exploration of the mass lesions (6). This can limit the use of mammography in the detection of breast lesions; however, complementary mammography may be used, particularly when screening non-mass lesions. These two medical imaging techniques make it possible to characterize the lesions found, and to identify any signs of malignancy or benignity $(6,7)$.

In Africa in general, and in Togo in particular, data regarding patients with cancer are scarce due to the unavailability of effective collection and collation tools, including a national cancer registry (8). The aims of the current study were to identify all cases of breast cancer in female patients $\leq 35$ years of age at the University Teaching Hospital of Lomé, and to record and analyze their epidemiological, histological and prognostic characteristics, whilst advocating for the establishment of a national cancer registry in Togo.

\section{Patients and methods}

The present study comprised a retrospective analysis of a series of breast cancer cases in female patients $\leq 35$ years that were diagnosed between January 2000 and December 2015 (15 years) at the University Teaching Hospital of Lomé (Lomé, Togo). These cases were collected from the registers contained within the hospital. The study material consisted of biopsy and surgical tissue specimens fixed in $10 \%$ formalin and treated according to conventional histology techniques (hematoxylin and eosin staining). Each cancer tissue sample was characterized according to the World Health Organization histological classification and graded according to the Scarff-Bloom-Richardson (SBR) system and prognostic stage of tumor-node-metastasis (TNM).

For immunohistochemical analysis carried out on certain tissue samples, the parameters were as follows: estrogen receptor (ER); progesterone receptor (PR); over expression of human epidermal growth factor receptor 2 (HER2). The imaging aspects observed during the ultrasound exam and mammography are considered. Ultrasound lesions were categorized as those with no associated malignant criteria and those with $\geq 1$ associated malignant criterion. On the ultrasonography-mammography pair, lesions were classified according to the Breast Imaging Reporting and Data System of the American College of Radiology.

Ethical consideration. The present study received approval from the Head of the Laboratory Department of the University Teaching Hospital of Lomé where the study was to be conducted. As the study included only records analysis, patient consent was not required. However, during the data collection and analysis, patient names were omitted in order to preserve confidentiality.

\section{Results}

Epidemiology. In the present study, 158 cases of breast cancer were collated, representing $\sim 38.3 \%(n=412)$ of all confirmed cases of breast cancer in female patients identified in the Department of Pathology of the University
Table I. Epidemiological characteristics of patients.

\begin{tabular}{lc}
\hline Characteristics & Values, $\mathrm{n}(\%)$ \\
\hline Age (year) & \\
Average & 30.9 \\
Extremes & $16-35$ \\
Location of the cancer & \\
Left Brest & $88(55.7)$ \\
Right Breast & $65(41.1)$ \\
Bilateral & $5(3.2)$ \\
Family history of cancer & \\
(1st and 2nd degree) & $22(13.9)$ \\
Breast cancer + pregnancy & $12(7.6)$ \\
\hline
\end{tabular}

Table II. Pathological characteristics of the patient cohort.

\begin{tabular}{lc}
\hline Characteristics & Values n $(\%)$ \\
\hline Histological type (n=158 cases) & \\
Canalar carcinoma & $119(75.3)$ \\
Lobular carcinoma & $12(7.6)$ \\
Mixed carcinoma & $13(8.2)$ \\
Other & $14(8.9)$ \\
Nuclear level (n=88 cases) & \\
Grade I & $19(21.6)$ \\
Grade II & $31(35.2)$ \\
Grade III & $38(43.2)$ \\
Tumor size (n=44 cases) & \\
T1 & $8(17.4)$ \\
T2 & $11(23.9)$ \\
T3 & $13(28.3)$ \\
T4 & $14(30.4)$ \\
Histological ganglionic involvement & \\
(n=36 cases) & \\
N+s3 & \\
N $>3$ & $20(56.6)$ \\
Hormonal receptors (n=23 cases) & $16(44.4)$ \\
ER+ PR+ & \\
ER- PR- & $7(30.4)$ \\
ER+ PR- & $4(17.4)$ \\
\end{tabular}

ER, estrogen receptor; PR, progesterone receptor; HER, human epidermal growth factor receptor; $\mathrm{T}$, tumor; $\mathrm{N}$, node.

Teaching Hospital of Lomé. The annual frequency was $10.5 \pm 1.6$ cases. The mean age at diagnosis was 30.9 years (range, 16-35 years), with $69.6 \%(n=110)$ of the patients being between 30 and 35 years of age. A total of 22 patients (13.9\%) had a familial history of breast cancer. Gene mutation studies were performed for 21 patients, and genetic mutations were observed in 3 patients ( 2 BRCA1 and 1 BRCA2). According to the location, the cancer was in the left breast in 88 cases 
Table III. Breast lesion characteristics according to the method of imaging used.

\begin{tabular}{llc}
\hline Imaging exam & \multicolumn{1}{c}{ Classification of lesion } & $\mathrm{n}(\%)$ \\
\hline Ultrasonography alone (n=72 cases) & No signs of malignancy & $5(3.16)$ \\
& $\geq 1$ sign of malignancy & $67(42.41)$ \\
Paired ultrasonography-mammography & BIRADS 1 (normal) & $0(0.00)$ \\
$(\mathrm{n}=86$ cases) & BIRADS 2 (benign lesion) & $1(0.63)$ \\
& BIRADS 3 (potential benign lesion) & $3(1.90)$ \\
& BIRADS 4 (potential malignant lesion) & $35(28.48)$ \\
& BIRADS 5 (malignant lesion) & $37(23.42)$ \\
\hline
\end{tabular}

BIRADS, Breast Imaging Reporting and Data System.

$(55.7 \%)$, the right breast in 65 cases $(41.1 \%)$ and bilateral in 5 cases $(3.2 \%)$. The 5 cases of bilateral cancer were all classified as $\mathrm{T} 4$, with lymph node invasion $(\mathrm{N}+)$ observed in 4 of these cases. The epidemiological characteristics of the patients are summarized in Table I.

Histopathology. The tissue samples examined consisted of 142 cases $(89.9 \%)$ of surgically resected tissues, including 79 nodulectomy cases and 63 mastectomy cases. Node dissection was associated with mastectomy in 44 cases. The average weights of the tissue samples were as follows: Nodulectomy (60 g); mastectomy (600 g). Specimens from micro-biopsies of breast lesions accounted for 16 cases (10.1\%). Tumor necrosis and hemorrhagic remodeling were identified in 98 cases (69\%). Histological, the malignant mammary lesions were either epithelial tumors $(n=144$ cases, 91.1\%), infiltrating $(\mathrm{n}=125$ cases, $79.1 \%$ ) or non-infiltrating ( $\mathrm{n}=19$ cases, $12.0 \%)$. The other histological groups consisted of 8 cases $(5.1 \%)$ of sarcomas ( 5 cases of angiosarcoma and 2 cases of fibrosarcoma and one case of Kaposi's sarcoma), 5 cases $(3.2 \%)$ of lymphomas and one case $(0.6 \%)$ of melanoma. Non-infiltrating epithelial tumors were observed at an average age of 27. 2 years, consisting of 17 cases of intra-ductal carcinoma and 2 cases of intra-lobular carcinoma.

Intracanal carcinomas consisted of comedocarcinoma subtypes in 11 cases $(64.7 \%)$, intracanal carcinoma of subtype mass in 3 cases and papillary carcinoma in 3 cases. Infiltrating epithelial tumors occurred at an average age of 30.6 years. Non-specific infiltrating ductal carcinoma $(n=102,81.6 \%)$ was the most frequent histological type of lobular carcinoma infiltrating $(n=10,8 \%)$ and mixed carcinoma $(n=13)$.

Non-specific infiltrating ductal carcinomas were SBR III $(n=38,43.2 \%)$, SBR II $(n=31,35.2 \%)$ and SBR I $(n=19,21.6 \%)$. The evaluation of the prognostic stage TNM of the carcinomas in 46 cases had noted: T4 $(n=14,30.4 \%)$, T3 $(n=13,28.3 \%)$, T2 $(\mathrm{n}=8,17.4 \%)$. Lymph node metastasis was recorded in 36 cases (22.8\%). Paget's disease of the nipple was present in 5 cases. Studies of hormone receptors were carried out in 23 patients and were positive for 11 patients: $\mathrm{ER}+\mathrm{PR}+$ (7 patients), ER+PR-(4 patients).

Immunohistochemical analysis of HER 2 was carried out in 17 patients, and was positive in 6 cases. These anatomopathological characteristics and findings are summarized in Table II. The 8 sarcomas cases consisted 5 angiosarcoma- cases, 2 fibrosarcomacases and one case of Kaposi's sarcoma. Lymphomas were all classified as Burkitt's lymphoma.

Imaging. The 158 patients had all undergone breast imaging (Table III). Overall, 72 (45.6\%) patient underwent mammary ultrasonography alone and 86 patients $(54.4 \%)$ underwent combined ultrasonography and mammography.

\section{Discussion}

Discussion of epidemiology. Breast cancer, due to the high global prevalence, presents a notable public health issue (3). The incidence of breast cancer varies markedly across the world; indeed, data from Northern countries that have a high technical plateau and cancer registries are challenging to compare with those of Southern countries typically do not $(8,9)$. Continuous and comprehensive recording of all cancer cases (cancer registry) is a guarantee of the quality of the data, and allows estimation of the incidence as well as the various epidemiological parameters (3-9). In France, the national incidence for cancer is estimated using data from the French network of cancer registries (FRANCIM) (10).

While the highest rates are recorded in the USA and Europe, they are also notably high in certain countries in South America, Asia and Africa (Brazil, Argentina, Pakistan, Kuwait and Egypt) $(8,10)$. In the current study, the proportion of breast cancer cases under 35 years of age was $38.3 \%$, comparable to data from the African series (11).

The relative risk associated with the presence of a family history of breast cancer is approximately 1.9 for all forms of kinship, and the excess risk is more pronounced in younger women and when the disease developed in a first-degree relative before the age of $50(1,2,12)$. Thoracic radiation, particularly when used in the treatment of cancer in children or young adults, increases the risk of developing breast cancer after 8 years (12).

This risk then continues to increase with age (12). According to Henderson et al (13), the cumulative risk at age 40 would be $10-19 \%$, equivalent to that of a female carrying a BRCA1 mutation. Other risk factors appear to be specific to non-menopausal female patients (13). Furthermore, a study published in 2006 suggested that the recent use of oral contraceptives, particularly in young nulligravidae was associated with an increased risk of breast cancer prior menopause (14). 
While obesity is a recognized risk factor in post-menopausal patients, it can function as a protective factor in young female patients $(13,14)$. The risk of breast cancer is also higher in young female patients of African descent, compared with in Caucasian female patients, as has been demonstrated in the USA (15).

Discussion of histopathology. Histologically, the predominance of infiltrating ductal carcinoma case reported in this series is corroborated in numerous reports in the literature databases $(9,11)$. Nodal invasion with capsular rupture in the current series was identified in $22.8 \%$ of cases, and in $40 \%$ in the case series presented by Bollet et al (16). Nodal invasion with capsular rupture in our series was found in $22.8 \%$ of cases and in $40 \%$ in the series of Bollet et al (16). The other series, unlike ours, report very little T3T4 $(17,18)$. Lammers et al (18) reported $9 \% \mathrm{~T} 3$ and $2 \% \mathrm{~T} 4$. The advanced stages observed in the current series were determined to be associated with delays in diagnosis; frequently, patients consulted health structures in very advanced clinical phases explaining the predominance of the highly evolved stages.

Given the delayed diagnosis, $\sim 75 \%$ of these cancer cases are diagnosed at an advanced stage, with $50-80 \%$ lymph node involvement and higher SBR grading (40\% SBR 2 and $50 \%$ SBR 3). Hormone receptors are less likely to be positive ( $68 \%$ of those $<40$ years of age vs. $80 \%$ of $\geq 40$ years), and HER 2 is more frequently over expressed in younger patients than in postmenopausal females $(19,20)$. Triple-negative tumors (negative for ER, PR and HER2) are more common in younger patients (21). Triple-negative breast cancer cases have a relapse pattern that is distinct from hormone-positive breast cancer cases: The risk of relapse is markedly higher for the first 3-5 years, but subsequently decreases abruptly and becomes notably lower than that for hormone-positive cancer cases $(21,22)$. Mammary sarcomas and lymphomas were rare in current series, concordant with the data from the literature that indicated the rates of these subtypes vary between 0.4 and $2 \%$ of all malignant breast tumors $(23,24)$.

Discussion of imaging. The imaging diagnosis of breast cancer cases is based on paired ultrasonography-mammography $(6,7)$. Mammography carried out in organized screening situations is typically administered only to female patients aged 50-74 years, but can be requested outside organized breast cancer screening under certain conditions, including the presence of certain symptoms, including pain or a mass $(25,26)$. Ultrasound is the recommended initial diagnostic test administered to young female patients, due to the high density of the breast tissue rendering the mammography images challenging to analyze. Younger female patients generally have denser breast tissue than older female patients. This variation is due to the physiological modification of the breast over the course of life, with decreased water overload and fibro glandular tissue becoming proportionately less important than fatty tissue (27).

In conclusion, the present study demonstrated that cases of breast cancer in female patients $\leq 35$ years of age are frequent in Togo, despite unavailability of a national cancer registry and immunohistochemistry techniques. These breast cancer cases are predominantly infiltrative ducal carcinoma of the breast, typically diagnosed in the advanced stages. These cases of breast cancer in young female patients require attention with regard to early diagnosis for adequate therapeutic management, particularly in countries with limited resources. The results indicate a genetic origin and warrant a thorough search. In addition, collaboration with other pathologists and institutions is required in future studies.

\section{Acknowledgements}

Dr Tchin Darré and Dr Mazamaesso Tchaou were responsible for the design of the study, undertook the field study, performed the data collection, data analysis and interpretation, and composed the manuscript. Dr Koué Folligan, Dr Abdoulatif Amadou, Dr Bidamin N'Timon, Dr Lantam Sonhaye, Dr Abdoul-Samadou Aboubakari, Dr Koffi Amégbor and Professor Koffi Akpadza participated in the design of the study, supervised the data collection and participated in the data analysis. Professor Gado Napo-Koura was responsible for the management of the study, the data analysis and interpretation, and the preparation of the final manuscript. All authors have read and approved the final manuscript to be submitted for publication.

\section{References}

1. Pollán M: Epidemiology of breast cancer in young women. Breast Cancer Res Treat 123 (Suppl 1): S3-S6, 2010.

2. Ferlay J, Steliarova-Foucher E, Lortet-Tieulent J, Rosso S, Coebergh JW, Comber H, Forman D and Bray F: Cancer incidence and mortality patterns in Europe: Estimates for 40 countries in 2012. Eur J Cancer 49: 1374-1403, 2013.

3. Anderson WF, Chatterjee N, Ershler WB and Brawley OW: Estrogen receptor breast cancer phenotypes in the surveillance, epidemiology and end results database. Breast Cancer Res Treat 76: 27-36, 2002.

4. Eng C, Schneider K, Fraumeni JF Jr and Li FP: Third international workshop on collaborative interdisciplinary studies of p53 and other predisposing genes in Li-Fraumeni syndrome. Cancer Epidemiol Biomarkers Prev 6: 379-383, 1997.

5. Partridge AH, Pagani O, Abulkhair O, Aebi S, Amant F, Azim HA Jr, Costa A, Delaloge S, Freilich G, Gentilini OD, et al: First international consensus guidelines for breast cancer in young women (BCY1). Breast 23: 209-220, 2014

6. Lacombe J, Mangé A, Bougnoux AC, Prassas I and Solassol J: A multiparametric serum marker panel as a complementary test to mammography for the diagnosis of node-negative early-stage breast cancer and DCIS in young women. Cancer Epidemiol Biomarkers Prev 23: 1834-1842, 2014

7. Perry NM, Patani N, Milner SE, Pinker K, Mokbel K, Allgood PC and Duffy SW: The impact of digital mammography on screening a young cohort of women for breast cancer in an urban specialist breast unit. Eur Radiol 21: 676-682, 2011.

8. Fregene A and Newman LA: Breast cancer in sub-Saharan Africa: How does it relate to breast cancer in African-American women? Cancer 103: 1540-1550, 2005.

9. Greenlee RT, Murray T, Bolden S and Wingo PA: Cancer statistics, 2000. CA Cancer J Clin 50: 7-33, 2000.

10. Le Guyader-Peyrou S, Belot A, Maynadié M, Binder-Foucard F, Remontet L, Troussard X, Bossard N and Monnereau A; French network of cancer registries (Francim): Cancer incidence in France over the 1980-2012 period: Hematological malignancies. Epidemiol Sante Publique 64: 103-112, 2016.

11. Gueye M, Kane Gueye SM, Ndiaye Gueye MD, Niasse Dia F, Gassama O, Diallo M and Moreau JC: Breast cancer in women younger than 35 years: Features and outcomes in the breast unit at aristide le dantec teaching hospital, dakar. Med Sante Trop 26: 377-381, 2016.

12. Assi HA, Khoury KE, Dbouk H, Khalil LE, Mouhieddine TH and El Saghir NS: Epidemiology and prognosis of breast cancer in young women. J Thorac Dis 1 (5 Suppl): S2-S8, 2013. 
13. Henderson TO, Amsterdam A, Bhatia S, Hudson MM, Meadows AT, Neglia JP, Diller LR, Constine LS, Smith RA, Mahoney MC, et al: Systematic review: Surveillance for breast cancer in women treated with chest radiation for childhood, adolescent, or young adult cancer. Ann Intern Med 152: 444-455, 2010.

14. Meynard G,Mansi L,LebaharP,Villanueva C,KlajerE,CalcagnoF, Vivalta A, Chaix M, Collonge-Rame MA, Populaire C, et al: First description of a double heterozygosity for BRCA1 and BRCA2 pathogenic variants in a French metastatic breast cancer patient: A case report. Oncol Rep 37: 1573-1578, 2017.

15. Anderson WF, Rosenberg PS, Menashe I, Mitani A and Pfeiffer RM: Age-related crossover in breast cancer incidence rates between black and white ethnic groups. J Natl Cancer Inst 100: 1804-1814, 2008.

16. Bollet MA, Sigal-Zafrani B, Mazeau V, Savignoni A, de la Rochefordière A, Vincent-Salomon A, Salmon R, Campana F, Kirova YM, Dendale R and Fourquet A: Age remains the first prognostic factor for loco-regional breast cancer recurrence in young $(<40$ years) women treated with breast conserving surgery first. Radiother Oncol 82: 272-280, 2007.

17. Chan A, Pintilie M, Vallis K, Girourd C and Goss P: Breast cancer in women < or=35 years: Review of 1002 cases from a single institution. Ann Oncol 11: 1255-1262, 2000.

18. Lammers EJ, Huibers P, van der Sangen MJ, van de Poll-Franse LV, Poortmans PM, Ernst MF, Lemaire BM, Meijs CM, Nuytinck HK and Voogd AC: Factors contributing to improved local control after mastectomy in patients with breast cancer aged 40 years or younger. Breast 19: 44-49, 2010.

19. Gentilini O, Botteri E, Rotmensz N, Toesca A, De Oliveira H, Sangalli C, Colleoni M, Intra M, Galimberti V, Veronesi P, et al: Breast-conserving surgery in 201 very young patients ( $<35$ years). Breast 19: 55-58, 2010.
20. Gonzalez-Angulo AM, Broglio K, Kau SW, Eralp Y, Erlichman J, Valero V, Theriault R, Booser D, Buzdar AU, Hortobagyi GN and Arun B: Women age $<$ or $=35$ years with primary breast carcinoma: Disease features at presentation. Cancer 103: 2466-2472, 2005.

21. Effi AB, Aman NA, Koui BS, Koffi KD, Traoré ZC and Kouyate M: Immunohistochemical determination of estrogen and progesterone receptors in breast cancer: Relationship with clinicopathologic factors in 302 patients in ivory coast. BMC Cancer 17: 115, 2017.

22. Albrektsen G, Heuch I and Thoresen SØ: Histological type and grade of breast cancer tumors by parity, age at birth and time since birth: A register-based study in Norway. BMC Cancer 10: 226, 2010

23. Navarrete E, Janser JC, Pusel J, Rodier JF and Rodier D: Sarcoma of the breast. J Chir (Paris) 125: 501-509, 1988 (In French).

24. Prévot S, Hugol D, Le Tourneau A, Audouin J and Diebold J: Primary non-Hodgkin's malignant lymphoma of the breast. Anatomopathologic diagnosis of 14 cases. Bull Cancer 77: 123-136, 1990.

25. Narayan AK, Visvanathan K and Harvey SC: Comparative effectiveness of breast MRI and mammography in screening young women with elevated risk of developing breast cancer: A retrospective cohort study. Breast Cancer Res Treat 158: 583-589, 2016.

26. Lee SY, Jeong SH, Kim YN, Kim J, Kang DR, Kim HC and Nam CM: Cost-effective mammography screening in Korea: High incidence of breast cancer in young women. Cancer Sci 100: 1105-1111, 2009.

27. Chérel P, Hagay C, Benaim B, De Maulmont C, Engerand S, Langer A and Talma V: Mammographic evaluation of dense breasts: Techniques and limits. J Radiol 89: 1156-1168, 2008. 